\title{
Erratum to: Human Aspects of Visualization
}

\author{
Achim Ebert ${ }^{1}$, Alan Dix ${ }^{2}$, Nahum D. Gershon ${ }^{3}$, and Margit Pohl ${ }^{4}$ \\ 1 University of Kaiserslautern, Computer Graphics and HCI, \\ Gottlieb-Daimler-Straße, 67663 Kaiserslautern, Germany \\ ebert@cs.uni-kl.de \\ ${ }^{2}$ Lancaster University, Computing Department, Lancaster, LA1 4WA, UK \\ alan@hcibook.com \\ 3 The MITRE Corporation, 7515 Colshire Drive, McLean, VA 22102-7539, USA \\ gershon@mitre.org \\ 4 Institute of Design and Assessment of Technology, \\ Vienna University of Technology, Favoritenstraße 9-11/E 187, 1040 Vienna, Austria \\ margit@igw.tuwien.ac.at
}

\section{Erratum to:}

\section{A. Ebert et al. (Eds.) \\ Human Aspects of Visualization \\ DOI: $10.1007 / 978-3-642-19641-6$}

The book was inadvertently published with an incorrect name of the copyright holder. The name of the copyright holder for this book is: (C) IFIP International Federation for Information Processing. The book has been updated with the changes.

The updated original online version for this book can be found at DOI: $10.1007 / 978-3-642-19641-6$
A. Ebert et al. (Eds.): HCIV (INTERACT) 2009, LNCS 6431, p. E1, 2011.
(C) IFIP International Federation for Information Processing 2017 